\title{
IMMUNOPATHOGENESIS OF CORONAVIRUS INFECTIONS: IMPLICATIONS FOR SARS
}

\begin{abstract}
Stanley Perlman ${ }^{\star \star s}$ and Ajai A. Dandekar
Abstract | At the end of 2002, the first cases of severe acute respiratory syndrome (SARS) were reported, and in the following year, SARS resulted in considerable mortality and morbidity worldwide. SARS is caused by a novel species of coronavirus (SARS-CoV) and is the most severe coronavirus-mediated human disease that has been described so far. On the basis of similarities with other coronavirus infections, SARS might, in part, be immune mediated. As discussed in this Review, studies of animals that are infected with other coronaviruses indicate that excessive and sometimes dysregulated responses by macrophages and other pro-inflammatory cells might be particularly important in the pathogenesis of disease that is caused by infection with these viruses. It is hoped that lessons from such studies will help us to understand more about the pathogenesis of SARS in humans and to prevent or control outbreaks of SARS in the future.
\end{abstract}

Viral infection of mammals results in certain typical responses by the host immune system. These responses are initiated by the innate immune system, which recognizes 'molecular patterns' (such as double-stranded RNA) that are unique to pathogens. The adaptive immune system - which consists of $\mathrm{T}$ cells that can kill virus-infected cells and B cells that produce pathogen-specific antibodies - then proceeds to mount a response. Initiation of the adaptive and/or innate immune response results in the production of chemokines and other cytokines that induce a pro-inflammatory response and attract cells, such as neutrophils and macrophages, to sites of infection. These cells, in turn, might release cytotoxic substances, such as matrix metalloproteinases. Although these responses are crucial to clear the infection, all of these processes can cause damage to normal host tissues. Indeed, 'side-effects' of the immune response account for many of the signs and symptoms in human infections: for example, during infection with hepatitis B virus, hepatitis C virus, measles virus or respiratory syncytial virus ${ }^{1-3}$. Consequently, a 'normal' immune response often results in a transient disequilibrium of tissue homeostasis, and this is required for clearance of an infection but can contribute to disease. In this Review, we consider any immune response that results in an increase in clinical disease or tissue destruction to be immunopathological.

In many cases, immunopathogenesis is the outcome of immune dysregulation rather than of a normal response (TABLE 1). This could occur in one of three ways. First, viral infection might result in an intense inflammatory response that compromises physiological function or results in excessive destruction of host tissue. In this situation, viral infection might interfere with the normal feedback mechanisms that control inflammation, and proinflammatory chemokines or other cytokines might be produced in large amounts or for an excessive period. For example, induction of expression of the pro-inflammatory cytokine interleukin-6 (IL-6) is a 
Table 1 | Mechanisms of immunopathogenesis

\begin{tabular}{|c|c|c|c|}
\hline Mechanism & Description & Coronavirus example & References \\
\hline $\begin{array}{l}\text { Inflammatory } \\
\text { storm }\end{array}$ & $\begin{array}{l}\text { Excessive host response to pathogen occurs, resulting in } \\
\text { either increased severity of localized disease or systemic } \\
\text { disease; excessive response might be non-specific or } \\
\text { induced by specific viral proteins; and manifestations } \\
\text { might also occur as part of the 'normal' immune response } \\
\text { required for viral clearance }\end{array}$ & MHV, FIPV, SARS-CoV & $7,8,40,59$ \\
\hline $\begin{array}{l}\text { Bystander } \\
\text { activation }\end{array}$ & $\begin{array}{l}\text { T cells that are not specific for the pathogen or any host } \\
\text { protein that is expressed at the site of inflammation are } \\
\text { nevertheless activated (possibly by cytokines), resulting in } \\
\text { increased tissue damage }\end{array}$ & $\mathrm{MHV}$ & 74,111 \\
\hline $\begin{array}{l}\text { Molecular } \\
\text { mimicry }\end{array}$ & $\begin{array}{l}\text { Pathogen and host share B- or T-cell epitopes, resulting in } \\
\text { an autoimmune reaction in the host tissue that expresses } \\
\text { the protein }\end{array}$ & None & - \\
\hline $\begin{array}{l}\text { Epitope } \\
\text { spreading }\end{array}$ & $\begin{array}{l}\text { Ongoing inflammation leads to presentation of self- } \\
\text { epitopes, resulting in an autoimmune reaction in the } \\
\text { host tissue that expresses the protein }\end{array}$ & MHV & 69 \\
\hline $\begin{array}{l}\text { Antibody- } \\
\text { dependent } \\
\text { enhancement }\end{array}$ & $\begin{array}{l}\text { Antibodies specific for cell-surface glycoproteins increase } \\
\text { virus uptake by macrophages, through cell-surface } \\
\text { Fc receptors, resulting in disease enhancement }\end{array}$ & $\begin{array}{l}\text { FIPV, possibly } \\
\text { SARS-CoV }\end{array}$ & $40,99,105$ \\
\hline
\end{tabular}

consequence of activation of p38 mitogen-activated protein kinase (p38MAPK) by the murine coronavirus, murine hepatitis virus $(\mathrm{MHV})^{4}$. Excessive production of pro-inflammatory mediators might then result in an unchecked influx of pro-inflammatory cells to the site of infection. Several of these types of cell, most notably neutrophils and macrophages, contribute to inflammation by producing toxic agents, such as reactive oxygen species, that kill both infected and normal cells at sites of infection, which would further exacerbate the response and result in immunopathological changes such as HAEMOPHAGOCYTOSIS ${ }^{5}$. Several of the released pro-inflammatory cytokines, such as tumour-necrosis factor (TNF), also induce apoptosis, which would result in increased tissue destruction. In addition, activated $\mathrm{T}$ cells that are not specific for the infecting virus or host antigens at the site of infection could traffic to sites of inflammation and contribute to tissue destruction, presumably through the production of chemokines or other cytokines. This has been shown for MHV-infected mice and is known as bystander activation (TABLE 1).

Second, direct infection of immune cells by a virus might cause increased or dysregulated production of immune mediators distinct from the aberrant production of chemokines and other cytokines previously discussed. For example, infection of mice with MHV strain 3 (MHV-3) results in production of the procoagulant prothrombinase by macrophages, leading to fulminant hepatitis and death ${ }^{6}$ (discussed in detail later).

Third, adaptive immune responses might become directed against host epitopes, and this would result in autoimmune reactions. Pathogen-specific antibodies or $\mathrm{T}$ cells might also recognize a host protein or epitope (through a process known as MOLECULAR MIMICRY). In other cases, prolonged infection and the ensuing tissue destruction might result in presentation of host-protein-derived T- or B-cell epitopes that were previously cryptic (through a process known as EPITOPE SPREADING). The response to these epitopes might prolong the inflammatory response, with consequent tissue destruction, even after virus has been cleared. These autoimmune responses would be limited to a certain tissue or cell type by the specificity of the immune cells involved. Several such mechanisms of autoimmune immunopathogenesis have been described for models of both coronavirus infection and non-coronavirus infection; these are described in TABLE 1.

Antibodies might also contribute to immunopathogenesis. With regard to coronaviruses, virus-specific antibody increases the uptake of several viruses by macrophages - including the feline coronavirus feline infectious peritonitis virus (FIPV) - resulting in activation of these macrophages and secretion of chemokines and other cytokines.

In several animal models of coronavirus infection, the immune system contributes considerably to the disease process - indeed, the pathology that is seen in several models is wholly, or at least partly, immune mediated. In this Review, we discuss the role of the immune system in the pathology that is seen in animals with coronavirus infections as a window onto the pathological processes that occur in humans infected with the severe acute respiratory syndrome (SARS) coronavirus (SARS-CoV). We focus on murine and feline coronavirus infections, because an immunopathological role in disease has been most clearly documented in these settings.

\section{SARS: a severe human coronavirus infection} In the winter of 2002-2003, SARS emerged in China and subsequently spread throughout the world. In the nine months between November 2002 and July 2003, 8,437 cases of this new disease, resulting 
ENZOOTIC VIRUS A virus that infects animals and is endemic to a geographical locale, with only minimal changes in its incidence over time. in 813 deaths, were reported to the World Health Organization by 29 countries. The aetiological agent of this disease, a coronavirus, was identified by several research groups in April 2003, and the virus has been named SARS-CoV after the syndrome it causes $^{7,8}$.

Coronaviruses are the largest of all of the RNA viruses, and they have a positive-sense, singlestranded RNA genome of 30-32 kilobases ${ }^{9}$ (FIG. 1). As a family, the Coronaviridae have a broad host range and cause a wide variety of gastrointestinal, respiratory and systemic diseases in animals, including infectious bronchitis in birds, a fatal disease with multi-organ involvement in felines, and enteritis in pigs, cows, turkeys and dogs. In humans, coronaviruses cause respiratory disease and, to a lesser extent, gastroenteritis. The viruses human coronavirus OC43 (HCoV-OC43) and $\mathrm{HCoV}-229 \mathrm{E}$ have long been known to be causative agents of the common cold, and the more recently identified agents HCoV-HKU1 and HCoV-NL63 cause more severe, although rarely fatal, infections of the upper and lower respiratory tract $^{10-12}$. SARS-CoV, which causes a much more severe respiratory disease, seems to be an ENZOOTIC VIRUs in Southeast Asia. Several species that might be infected, such as masked palm civets (Paguma larvata), are consumed as food in parts of China, and the 'wet markets', at which live animals are bought and sold, are likely venues for the initial crossover event to humans ${ }^{8}$. The 2002-2003 outbreak of SARS

\section{a SARS-CoV genome}

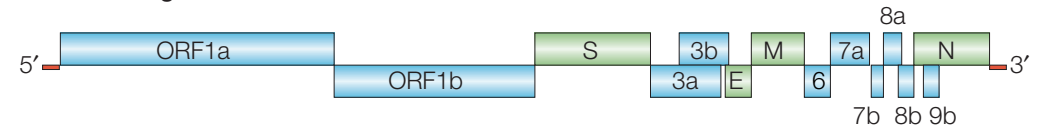

\section{b SARS-CoV virion}

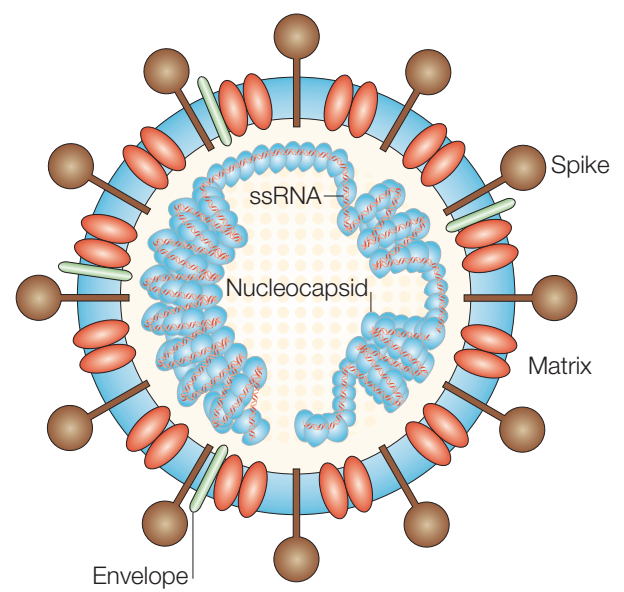

Figure 1 | The severe-acute-respiratory-syndrome coronavirus genome and virion. a | The severe-acute-respiratory-syndrome coronavirus (SARS-CoV) genome consists of 28 putative open reading frames (ORFs) in 9 mRNA transcripts. ORF1a and ORF1b, which account for about two-thirds of the genome, both encode large polyproteins. ORF1b protein is produced by a -1-base-pair ribosomal frameshift from the reading frame of ORF1a. The SARS-CoV genome encodes four structural proteins: spike (S), envelope (E), matrix (M) and nucleocapsid (N). In non-human isolates, transcription of ORF8a and ORF8b produces a single protein. $\mathbf{b} \mid$ A schematic representation of a SARS-CoV virion is shown. ssRNA, single-stranded RNA. in humans probably resulted from an interspecific transfer of the virus by aerosols from live, exotic animals that were infected with SARS-CoV to workers in these wet markets. Sera from masked palm civets, raccoon dogs (Nyctereutes procyonoides) and Chinese ferret-badgers (Melogale moschata) were shown to contain neutralizing antibodies that were specific for SARS-CoV, and virus that was nearly identical to the strains that were isolated from infected humans was detected in masked palm civets ${ }^{13-15}$. However, a specific animal reservoir for the virus has yet to be definitively identified.

Infection of humans with SARS-CoV typically causes an influenza-like syndrome of malaise, rigors, fatigue and high fevers. In two-thirds of infected patients, the disease progresses to an atypical pneumonia, with shortness of breath and poor oxygen exchange in the alveoli. Many of these patients also develop watery diarrhoea with active virus shedding, which might increase the transmissibility of the virus. Respiratory insufficiency leading to respiratory failure is the most common cause of death among those infected with SARS-CoV ${ }^{8}$. Consistent with these clinical observations, the host cell-surface receptor for SARS-CoV, angiotensin-converting enzyme 2 (ACE2), is detected in the lungs and gastrointestinal tract ${ }^{16,17}$. Because it binds ACE2, SARS-CoV might contribute to lung-tissue injury by a novel mechanism. ACE2 has a protective role during acute lung injury. By binding ACE2, SARS-CoV leads to the downregulation of ACE2 expression and might therefore negate the protective effect of ACE2. This mechanism of injury was shown in a mouse model using SARS-CoV spike glycoprotein, through which the virus binds ACE2, but it has not yet been confirmed in humans or animals that are infected with SARS-CoV ${ }^{18,19}$. Severe cases of SARS are associated with lymphopaenia, neutrophilia, mild thrombocytopaenia and coagulation defects ${ }^{20}$. Haemophagocytosis, which is indicative of cytokine dysregulation, is also detected in some patients with severe disease $\mathrm{e}^{21,22}$.

Damage to the lungs of patients who are infected with SARS-CoV seems to occur directly, by viral destruction of alveolar and bronchial epithelial cells and macrophages, as well as indirectly, through production of immune mediators, although the exact role of these direct and indirect mechanisms remains controversial. Viral load, as determined from titres in nasopharyngeal aspirate, diminishes 10-15 days after the onset of symptoms, even though clinical disease and alveolar damage worsen, indicating that the host immune response is responsible for some of the pathology in SARS-CoV-infected patients ${ }^{23,24}$. However, nasopharyngeal viral titres do not necessarily reflect viral loads in the lungs, and high concentrations of virus have been detected in several organs at autopsy, including the lungs, intestine, kidneys and brain $^{25-27}$.

Infection of macrophages and lymphocytes is likely to be a key component in SARS-CoV-induced pathogenesis. SARS-CoV directly infects T cells, contributing 
ABORTIVE INFECTION

An infection in which viral replication is initiated but no infectious virus is produced.

SEROSITIS

Inflammation of the membranes that line the lungs (the pleura), the heart (the pericardium), and the abdomen (the peritoneum) and the organs within.

PYOGRANULOMATOUS VASCULITIS

A type of vasculitis (that is, inflammation of the blood vessels) that is associated with a chronic inflammatory process in which neutrophils are mixed with components of granulomas.

ASCITIC FLUID

Serous fluid that accumulates in the abdominal cavity. It might result from serositis. to lymphopaenia and to atrophy of the spleen and lymphoid tissue ${ }^{25}$. The murine coronavirus MHV-3 also infects and destroys lymphocytes, thereby facilitating viral replication and persistence ${ }^{28}$. SARS-CoV-infected lymphocytes, similar to FIPV-infected macrophages in domestic cats, might transport the virus to distant organs, resulting in systemic infection ${ }^{25}$. Macrophages, both infected and uninfected, are detected in large numbers in the lungs of patients who died as a result of SARS ${ }^{22,25,29}$. Although infected macrophages have been found in vivo, SARS-CoV causes an ABORTIVE INFECTION of these cells in vitro ${ }^{30-32}$. SARS-CoV also interferes with the initiation of the innate immune response by inhibiting the expression of type I interferons (IFNs) by infected cells, including human monocyte-derived dendritic cells (DCs) and macrophages. IFN production requires the phosphorylation and dimerization of a constitutively expressed protein, IFN-regulatory factor 3 (IRF3). IRF3 is not activated, at least in vitro, after infection with SARS-CoV ${ }^{30-34}$. By contrast, expression of chemokines such as CXC-chemokine ligand 10 (CXCL10), CC-chemokine ligand 2 (CCL2), CCL3, CCL5 and CCL8 is upregulated by abortively infected DCs and macrophages and might contribute to the influx of monocytes and/or macrophages that is observed in infected tissues ${ }^{30,34}$; CXCL10 and CCL2 expression are also upregulated in the blood of patients with SARS ${ }^{35}$. Expression of CXCL8 (also known as IL-8), which is an attractant for neutrophils, is also upregulated in the serum of patients with SARS ${ }^{35-37}$. Consistent with a role for CXCL8 in pathogenesis, severe disease is associated with an increase in the number of neutrophils in the blood ${ }^{20,38}$.

Although these studies indicate that upregulation of expression of pro-inflammatory molecules contributes to the pathogenesis of SARS, increased serum concentrations of two anti-inflammatory molecules - transforming growth factor- $\beta$ and prostaglandin $E_{2}$ - were detected in another study ${ }^{39}$. Increased concentrations of these anti-inflammatory molecules might impair clearance of virus. The mechanism by which chemokines and other cytokines are regulated in infected patients is not known, but SARS-CoV induces the activation of p38MAPK in monocytes $^{39}$. The murine coronavirus, MHV, also induces p38MAPK activation, and inhibition of p38MAPK activation results in decreased production of infectious $\mathrm{MHV}^{4}$. Induction of p38MAPK expression by MHV results in production of IL- 6 and phosphorylation of eukaryotic translation-initiation factor $4 \mathrm{E}$ (EIF4E), which increases cap-dependent (including MHV-specific) protein production. By analogy, it is possible that increased cytokine production by the monocytes of patients with SARS might be an untoward consequence of a mechanism that is used by the virus to increase replication in some cells ${ }^{4}$.

Together, these findings are consistent with models in which the immune system contributes to the SARS disease process. Understanding the immunopathogenesis of SARS could provide new insights into effective treatments for this illness.

\section{Feline coronavirus infections}

Macrophage infection and dysfunction. Feline enteric coronaviruses (FECVs) generally cause mild or asymptomatic infections, mainly of domestic cats, although cases have been reported in wild feline populations ${ }^{40}$. Domestic cats often become persistently infected with FECV. Occasionally, these animals develop the uniformly fatal disease infectious peritonitis, which is caused by a macrophage-tropic variant of FECV that is known as FIPV. Indeed, virulent strains of FIPV replicate more efficiently in feline peritoneal macrophages in vitro than do avirulent strains of FECV ${ }^{41}$. However, most strains of FIPV are antigenically identical to their avirulent FECV counterparts, and the genetic changes that are responsible for the gain in virulence are not well understood.

In an elegant longitudinal study, de Groot and colleagues ${ }^{42}$ showed that domestic cats that were experimentally infected with FIPV developed a multiphasic disease. Initially, all animals developed fever, weight loss and lymphopaenia but could contain the infection. Total lymphocyte counts recovered with time; however, in most animals, the infection relapsed, as was shown by an increase in viral load. These increased viral burdens resulted in repeated bouts of disease, which again coincided with fever, weight loss and lymphopaenia. FIPV-infected felines develop histological evidence of SEROSITIS and PYOGRANULOMATOUS VASCULITIS. In the more common 'wet' form of FIP (also known as the effusive form), yellow ASCITIC FLuid gradually accumulates as the disease progresses; there is also a 'dry' form of the disease, which does not involve the accumulation of ascitic fluid. Antigen-antibody-complex formation and complement activation occur in the late stages of disease and might contribute to the production of ascitic fluid in the wet form of disease ${ }^{43}$.

The clinical signs and lymphocyte depletion are postulated to be a direct consequence of the infection of macrophages and DCs by FIPV. In support of this idea, both macrophages and DCs express CD13 (also known as aminopeptidase $\mathrm{N}$ ), the receptor for FIPV, and infection of macrophages by FIPV has been shown in vitro ${ }^{41,44}$ (FIG. 2a,b). Infected macrophages traffic throughout the body, resulting in a disseminated infection. In lymph nodes, infection of macrophages and DCs might alter the interaction of these cells with T cells so that they dampen, rather than reinforce, the FIPV-specific T-cell response. This might occur through induction of expression of IL-10 (probably produced by macrophages), which is present in increased amounts in infected lymph nodes ${ }^{45}$. The production of IL-10 might skew the immune response away from a protective $\mathrm{T}$ helper $1\left(\mathrm{~T}_{\mathrm{H}} 1\right)$-cell response towards a non-protective $\mathrm{T}_{\mathrm{H}} 2$-cell response, thereby diminishing the ability of immune cells to clear the virus. Regarding the lymphopaenia, lymphocyte apoptosis is commonly observed in infected lymphoid tissues, although lymphocytes are not themselves infected by the virus ${ }^{42,46,47}$. So, lymphoid-cell depletion is probably mediated by a soluble factor. In support of this idea, 
a Macrophage infection and dysfunction

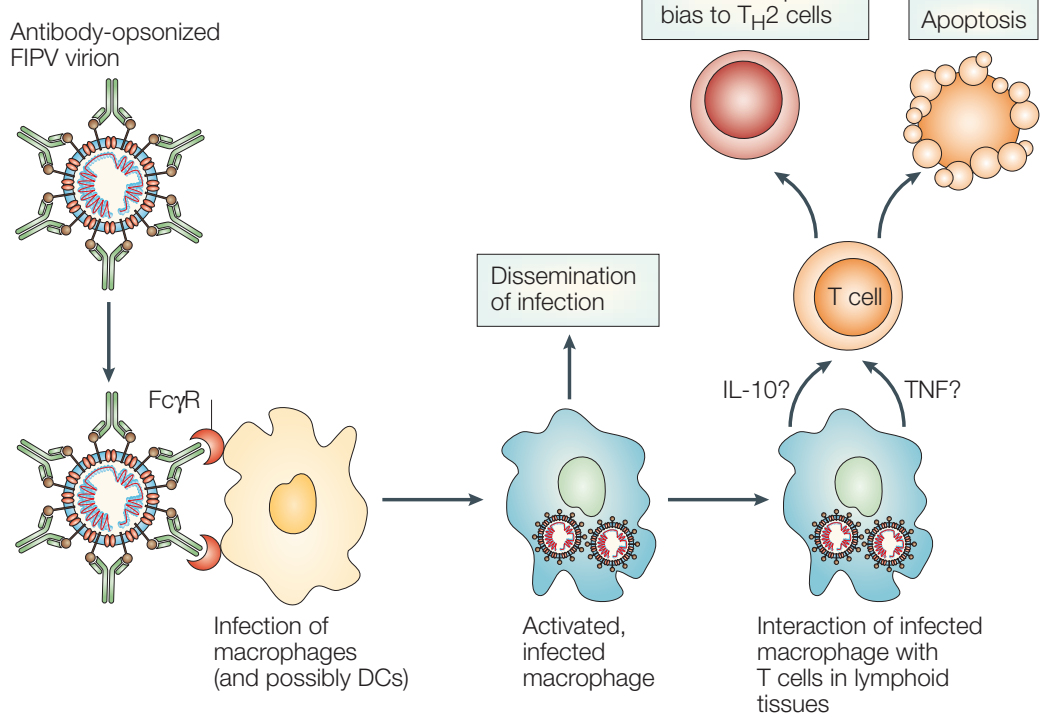

b Coronavirus-receptor-mediated entry

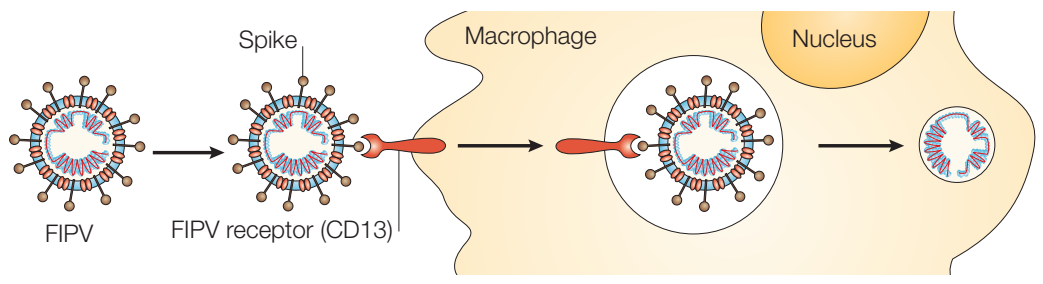

c Antibody-dependent enhancement of entry

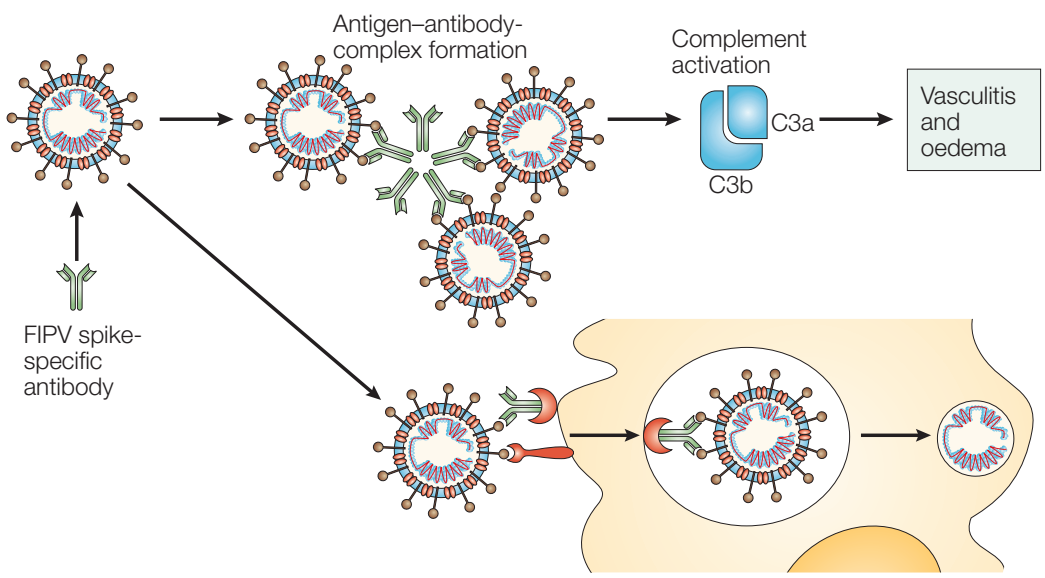

Figure 2 | Macrophage infection and antibody-dependent enhancement of virus entry in infection with feline infectious peritonitis virus. a | Infection of macrophages and possibly dendritic cells (DCs) results in both dissemination of feline infectious peritonitis virus (FIPV) infection and dysregulation of these cells, leading to lymphocyte apoptosis. b | FIPV usually infects cells through the binding of the spike protein to its cellular receptor, CD13. The virus is then internalized and released into the cytoplasm. c $\mid$ In antibody-dependent entry, specific antibodies bind the spike protein. The antibody-opsonized FIPV virions then interact with FcyRs (receptors for lgG). Some evidence indicates that this process augments the normal spike-CD13 interaction. After binding of the opsonized virions to FcyRs, the virus is internalized and released into the cytoplasm. Antigen-antibody complexes are also deposited in the vasculature, resulting in complement activation. Activation of complement contributes to the development of vasculitis and oedema, with death of the animal occurring soon after. C3, complement component 3; IL-10, interleukin-10; $T_{H} 2$ cell, T helper 2 cell; TNF, tumour-necrosis factor. conditioned media from peritoneal or splenic cells that were isolated from infected domestic cats and cultured in vitro induced the apoptosis of $\mathrm{T}$ cells ${ }^{46}$. The specific factor that is responsible for apoptosis has not yet been identified, although TNF, a factor that is implicated in lymphocyte apoptosis, is detected at increased levels in domestic cats with FIP $^{48,49}$. By contrast, domestic cats that are exposed to FIPV but do not develop disease show lymphoid hyperplasia, which is consistent with the development of a protective T-cell response $\mathrm{e}^{50}$.

Antibody-dependent enhancement of FIPV infection. As disease progresses, FIPV-infected macrophages are deposited in the endothelium of small blood vessels in organs such as the liver, spleen and kidneys, and GRANULOMAS subsequently form at these sites. Granulomas consist of monocytes and/or macrophages, $\mathrm{B}$ cells and $\mathrm{CD} 4^{+} \mathrm{T}$ cells, with only small amounts of virus detected ${ }^{51,52}$. These pyogranulomatous lesions are associated with severe damage to the endothelium and are responsible for many of the manifestations of disease, such as liver and renal disease, in infected domestic cats.

Another manifestation of FIP is B-cell hyperplasia with associated hypergammaglobulinaemia. Although the aetiology of B-cell hyperplasia is not known, it most probably results from aberrant cytokine production by infected macrophages. Neutralizing antibodies that are raised during FIPV infection and other coronavirus infections are mainly directed against spike protein. In the case of FIPV, however, the presence of these antibodies does not provide sterilizing immunity. Instead, these antibodies opsonize virus particles and facilitate their entry to monocytes and/or macrophages through Fc $\gamma$ receptors (receptors for IgG) ${ }^{40}$ (FIG. 2a,c). Furthermore, antigen-antibody complexes are deposited in the blood-vessel walls. These complexes activate complement, leading to vasculitis and oedema, and might thereby contribute to the development of the wet form of $\mathrm{FIP}^{40}$. Antigen-antibody-complex formation and its consequences occur late in the course of disease and are predictive of a poor outcome ${ }^{53}$. Indeed, the humoral response that develops in FECV-immune domestic cats does not protect animals against FIPV infection and might contribute to a particularly fulminant disease known as early death syndrome. This 'enhanced' form of disease has not been documented for animals that are naturally infected but has been shown for domestic cats that are passively or actively immunized against FIPV. Administration of spikeprotein-specific antibodies to uninfected domestic cats or active immunization of domestic cats with recombinant vaccinia virus that expresses spike protein results in an accelerated disease course after infection with FIPV $^{54,55}$. This syndrome does not develop in FECVinfected domestic cats, possibly reflecting the ability of FIPV to replicate more efficiently in macrophages. This accelerated pathogenesis of FIPV in immunized animals provides strong support for the idea that the immune response is an important contributing factor to disease. 
GRANULOMA

A collection of modified macrophages that resemble epithelial cells. This is usually lymphocytes that often includes multinucleated giant cells. Granuloma formation is a chronic inflammatory response that is initiated by various infectious and non-infectious agents. surrounded by a layer of

\section{Murine coronavirus infections}

Immune-mediated demyelination: the result of an excessive immune response? Several strains of MHV cause acute and chronic neurological diseases in susceptible mice and rats. The JHM and A59 strains of MHV cause demyelination; this infection has been intensively studied because it is a useful model of the human disease multiple sclerosis ${ }^{56-58}$. In early studies, demyelination was thought to result from virus-mediated lysis of infected cells ${ }^{59,60}$. However, it is now clear that myelin destruction is largely immune mediated (FIG. 3). Accordingly, mice that receive sub-lethal doses of irradiation or are congenitally immunodeficient (such as mice with severe combined immunodeficiency (SCID) or mice that are deficient in recombination-activating gene 1 (Rag1) activity) do not develop demyelination after infection with MHV-JHM ${ }^{61-64}$. Both $\mathrm{Rag1}^{-/-}$and SCID mice lack $\mathrm{T}$ and $\mathrm{B}$ cells but have normal numbers of macrophages and natural killer cells.

In one model of infection, an attenuated variant of MHV-JHM (MHV-JHM 2.2-V-1) with a tropism for oligodendrocytes is used to inoculate susceptible mice (usually C57BL/6 or BALB/c mice) ${ }^{61,65-68}$. These mice develop signs of demyelination, including hind-limb paralysis and gait disturbances, by 7 days after infection. The virus is cleared by $12-14$ days after infection, but the neurological deficits persist. MHV-JHM infection of the central nervous system (CNS) results in

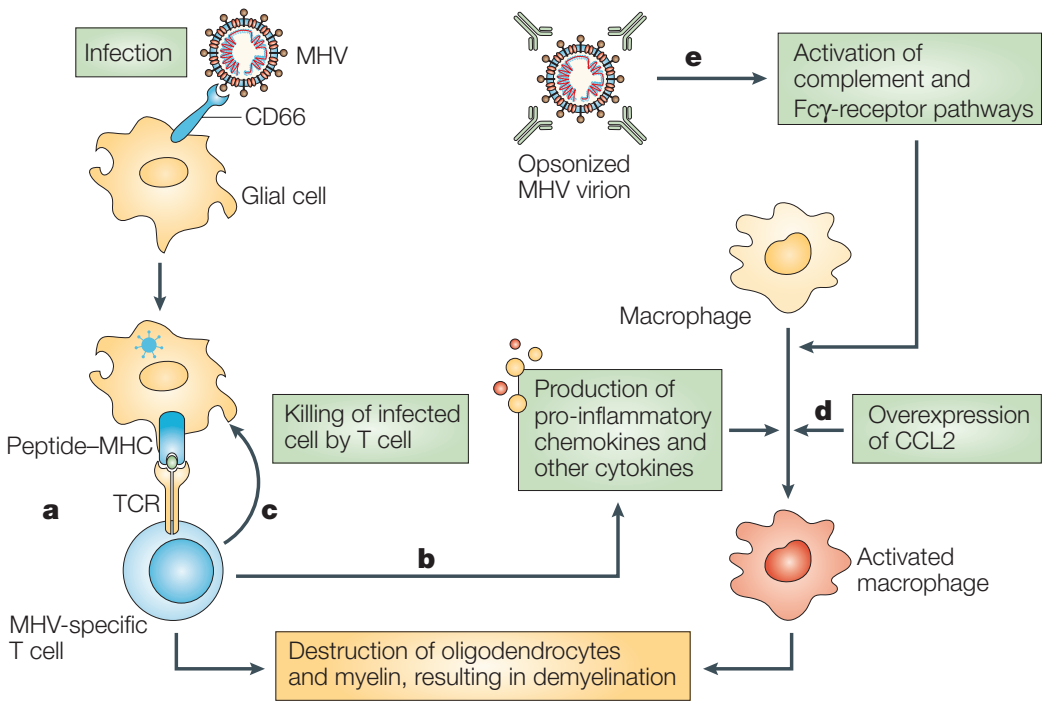

Figure 3 | Mechanisms of immune-mediated demyelination in infection with murine

hepatitis virus. In immunocompetent mice, infection of glial cells (that is, astrocytes, microglia and oligodendrocytes) results in migration of T cells into the central nervous system (a). Myelin destruction is mediated by $\mathrm{CD} 4^{+}$and $\mathrm{CD} 8^{+} \mathrm{T}$ cells, and these cells activate macrophages by the production of cytokines $(\mathbf{b})$ or kill infected cells directly $(\mathbf{c})$, both of which result in demyelination. In recombination-activating gene $1(\operatorname{Rag} 1)^{-1-}$ mice, which lack $T$ and $B$ cells, two additional mechanisms of demyelination have been elucidated. Rag $1^{-/-}$mice do not develop demyelination when infected with the JHM strain of murine hepatitis virus (MHV-JHM); as occurs in immunocompetent mice, demyelination develops after the adoptive transfer of MHV-JHM-specific T cells. However, demyelination also results if infected Rag $1^{1^{-/}}$mice are infected with a recombinant MHV-JHM expressing the macrophage attractant CC-chemokine ligand 2 (CCL2) (d), presumably by direct activation of macrophages. Similarly, exogenous delivery of neutralizing MHV-JHM-specific antibody (e) results in macrophage activation and demyelination; this process depends on activation through complement and activating Fc $\gamma$ receptors (receptors for $\lg G$ ). TCR, T-cell receptor. a large infiltration of $\mathrm{B}$ cells and $\mathrm{CD} 4^{+}$and $\mathrm{CD} 8^{+} \mathrm{T}$ cells. $\mathrm{MHV}$-JHM-specific $\mathrm{CD} 8^{+} \mathrm{T}$ cells are required for initial clearance of virus, which occurs through perforin- and IFN- $\gamma$-dependent pathways, whereas MHV-JHMspecific antibody is required to prevent reactivation of virus ${ }^{61,65-67}$. However, the influx of these T cells also seems to set up a destructive cascade of cytokine production that results in demyelination. These T cells are mainly directed against MHV-JHM antigens, although in one report, the authors identified myelin-specific $\mathrm{CD}^{+} \mathrm{T}$ cells in the CNS of the infected rat (a possible example of epitope spreading ${ }^{69}$.

Histological evidence of demyelination is present in the spinal cords of MHV-JHM-infected mice, beginning at $\sim 5$ days after infection, with maximal myelin destruction occurring at 14-21 days after infection. Most tissue destruction occurs when infectious virus has been completely or partially cleared ${ }^{70,71}$. Viral antigens are not detected in areas of demyelination, whereas they are found in adjacent white matter that appears to be normal, indicating that myelin destruction is a direct consequence of clearance of virus ${ }^{72}$. Large influxes of activated macrophages and microglia are found in these areas of demyelination ${ }^{70}$, indicating that these cells have a crucial role in the pathological process.

Both $\mathrm{CD}^{+}$and $\mathrm{CD}^{+}$T cells can mediate disease $^{64,72}$. Mice that have defective MHC class I or class II expression and therefore lack $\mathrm{CD} 8^{+}$or $\mathrm{CD} 4^{+} \mathrm{T}$ cells, respectively, develop demyelination when infected with MHV-JHM or MHV-A59 (REFS 64,73). Other studies have used adoptive transfer of MHV-JHM-specific immune cells to infected Rag1 $1^{-1-}$ mice; in the absence of transferred cells, these mice do not develop demyelination after infection with MHV-JHM, but transfer of splenocytes results in robust demyelination. Infected $\mathrm{Ragl}^{-{ }^{-}}$ mice that are reconstituted with either $\mathrm{CD} 4^{+}$or $\mathrm{CD} 8^{+}$ $\mathrm{T}$ cells from a mouse that is immune to infection with MHV-JHM also develop demyelination. Demyelination can also be induced by $\mathrm{CD}^{+} \mathrm{T}$ cells that do not recognize viral or CNS antigens, if these T cells are sufficiently activated ${ }^{74}$ (a process that is known as bystander activation) (TABLE 1). Accordingly, MHV-JHM-infected Rag1 $1^{-1-}$ mice that expressed a single T-cell receptor specific for an epitope encoded by another virus (lymphocytic choriomeningitis virus) developed demyelination, but this only occurred when the transgenic $\mathrm{T}$ cells were activated by cognate antigen.

Although the antiviral T-cell response is crucial for MHV-JHM- or MHV-A59-induced demyelination in normal mice, MHV-JHM-specific antibodies (in the absence of any transferred T cells) can mediate demyelination in infected Rag1 ${ }^{-/-}$mice $^{75}$. Virus-specific T cells and antibodies activate macrophages and/or microglia, resulting in their migration into the white matter of the CNS and, subsequently, in demyelination. The activation and migration of macrophages and microglia might be the most crucial process for demyelination, because virus-encoded expression of a single macrophage attractant, CCL2, is sufficient to induce demyelination in MHV-JHM-infected Rag1 ${ }^{-1-}$ mice in the absence of transferred $\mathrm{T}$ cells or antibody ${ }^{76}$. 


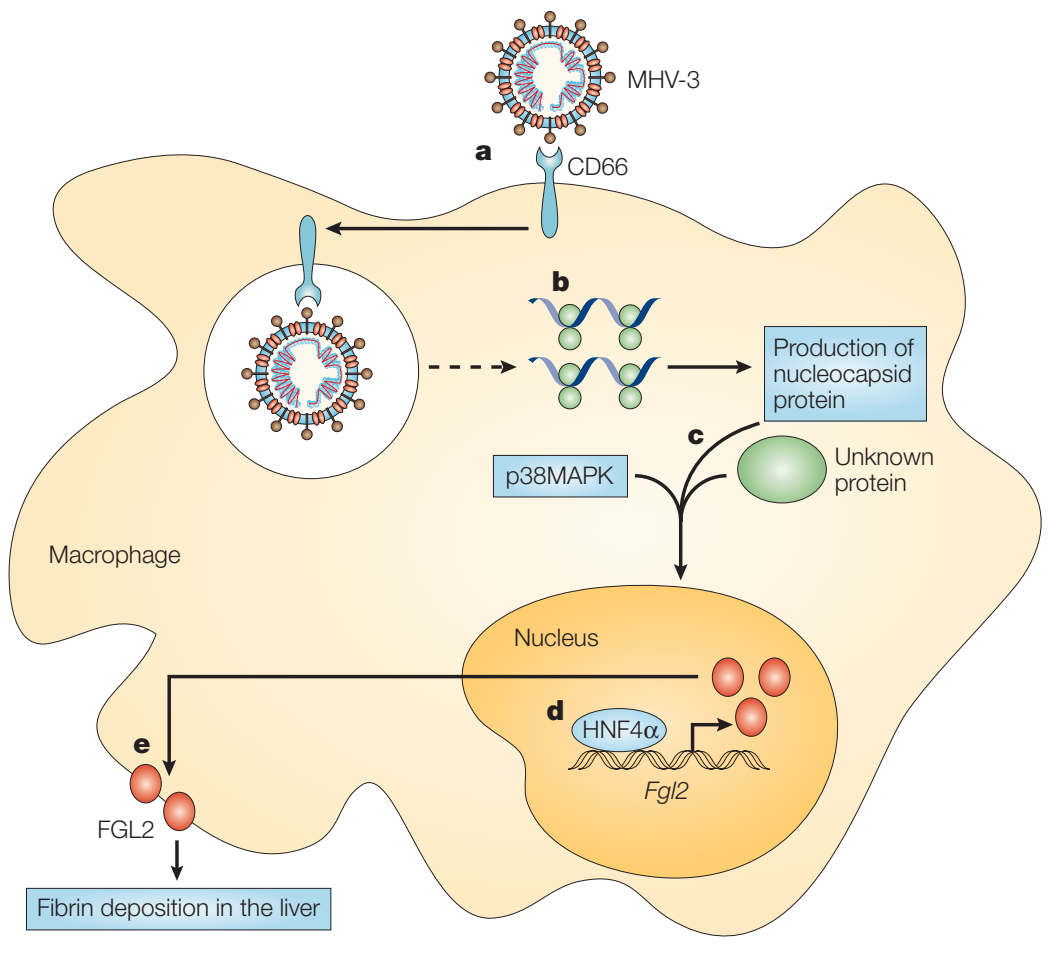

Figure 4 | Infection with murine hepatitis virus strain 3 results in upregulation of expression of fibrinogen-like protein 2. Murine hepatitis virus strain 3 (MHV-3) becomes internalized after binding macrophages through its receptor, CD66 (a). Subsequent to internalization, virions are uncoated and begin to replicate. As part of the replication process (b), the nucleocapsid protein is synthesized. Subsequently, a signalling pathway involving p38 mitogen-activated protein kinase (p38MAPK) activation, as well as the nucleocapsid protein and other unknown host factors, is initiated (c), resulting, ultimately, in binding of the transcription factor hepatocyte nuclear factor $4 \alpha(\mathrm{HNF} 4 \alpha)$ to the gene that encodes fibrinogen-like protein 2 (FGL2) (d), which is a prothrombinase. The FGL2 protein that is produced then translocates to the cell surface (e), where it induces fibrin deposition and, consequently, acute liver necrosis. macrophages is a cause of the immune dysregulation that is observed in these animals. Instead, a generalized, excessive, but perhaps appropriate, response by both infected and uninfected macrophages seems to be crucial for demyelination.

MHV-3-mediated lethal hepatitis: induction of expression of a novel prothrombinase. MHV-3 causes various diseases, with the outcome dependent on the strain, age and immune status of the mouse host ${ }^{85}$. Semisusceptible strains, such as $\mathrm{C} 3 \mathrm{H}$ mice and $\mathrm{F}_{1}$ crosses of resistant and susceptible strains, become persistently infected, which manifests mainly as neurological disease: ependymitis, encephalitis and hydrocephalus are hallmarks of this disease ${ }^{59}$. MHV-3-infected $\mathrm{C} 3 \mathrm{H}$ mice also develop a chronic thrombotic vasculitis, with viral antigen detected in endothelia. The pathogenesis of this disease is not well understood, but it is likely to be immune mediated. MHV-3, unlike the neurotropic MHV-JHM and MHV-A59 strains, infects T and $\mathrm{B}$ cells. This infection is largely non-productive but results in lymphocyte death, perhaps by apoptosis, with consequent cellular and humoral immunosuppression. This immunosuppression is an important contributory factor to the persistence of MHV-3 (REF. 28).

Infection of susceptible strains of mice with MHV-3 results in an acute hepatitis, with death occurring a few days after inoculation. The receptor for MHV-3, CD66 (also known as CEACAM1), is expressed by macrophages $^{86}$, and infection of these cells has a central role in the pathogenesis of the liver failure that is seen in these animals. Macrophages from susceptible mouse strains that are infected with MHV-3 upregulate the production of several pro-inflammatory molecules both in vitro and in vivo, including a transmembrane procoagulant molecule, fibrinogen-like protein 2 (FGL2;

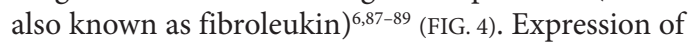
FGL2 results in cleavage of prothrombin to thrombin, which initiates the coagulation cascade that begins with fibrin deposition. This deposition of fibrin throughout the hepatic sinusoids and venous system results in inadequate perfusion or lack of perfusion to the liver and accelerates the necrosis that is caused by the direct cytotoxicity of MHV-3 to hepatocytes.

This upregulation of expression of the prothrombinase FGL2 occurs only in macrophages, monocytes and, to a lesser extent, endothelial cells in the liver of susceptible strains of mice, even though MHV-3 can also replicate in the liver-resident macrophages of resistant strains of mice. Upregulation of FGL2 expression by macrophages and monocytes correlates with the severity of liver disease considerably better than do viral titres. Expression of FGL2 depends on activation of p38MAPK, expression of the MHV-3 nucleocapsid protein, and binding of the transcription factor hepatocyte nuclear factor $4 \alpha(\mathrm{HNF} 4 \alpha)$, which is constitutively expressed by macrophages, to the Fgl2 promoter ${ }^{90,91}$. How the nucleocapsid protein induces $\mathrm{HNF} 4 \alpha$ binding to the promoter of Fgl2 is unknown; similarly, the factors that abrogate upregulation of FGL2 expression in resistant strains of mice are also unknown. 
Table 2 | Does SARS have an immunopathological component?

\begin{tabular}{|c|c|c|}
\hline Criterion & $\begin{array}{l}\text { Evidence in SARS-CoV } \\
\text { infection }\end{array}$ & Precedent in other coronavirus infections? \\
\hline $\begin{array}{l}\text { Worse disease with } \\
\text { decrease in viral load }\end{array}$ & $\begin{array}{l}\text { Controversial; viral titres, measured } \\
\text { in nasopharyngeal-aspirate } \\
\text { samples, decrease as clinical } \\
\text { disease worsens }{ }^{24,36} \text {; but high viral } \\
\text { loads have been detected in lungs }\end{array}$ & $\begin{array}{l}\text { MHV-induced demyelination increases as virus is } \\
\text { cleared }^{71} \text {; MHV-3-induced hepatitis correlates with } \\
\text { macrophage activation and not viral load }{ }^{87} \text {; and IBV- } \\
\text { induced nephritis is detected in chickens with very } \\
\text { low viral loads }\end{array}$ \\
\hline
\end{tabular}

\begin{tabular}{ll}
$\begin{array}{l}\text { Macrophage or DC } \\
\text { infection }\end{array}$ & $\begin{array}{l}\text { Infection is abortive but induces } \\
\text { expression of pro-inflammatory } \\
\text { mediators }\end{array}$ \\
\hline $\begin{array}{l}\text { Macrophage } \\
\text { infiltration into sites }\end{array}$ & $\begin{array}{l}\text { Macrophages are present in large } \\
\text { numbers in infected lungs }\end{array}$ \\
\hline
\end{tabular}

MHV and FIPV productively infect macrophages ${ }^{40,59}$

infiltration into sites numbers in infected lungs 22,29

In MHV infection, macrophages infiltrate the CNS coincident with demyelination (thought to be the final effector cell) ${ }^{62,76}$; and in FIPV infection, macrophages are the main cell type in granulomas and are crucial for pathogenesis $\mathrm{s}^{40,43,52}$

\section{High concentration of pro-inflammatory mediators in serum or at site of infection}

Inhibition of type I IFN induction in infected cells

Lymphopaenia and neutrophilia
Controversial; anti-inflammatory mediators might contribute to delayed viral clearance ${ }^{7,39}$ macrophages, DCs and fibroblasts $30,32-34$

Present in most severe cases ${ }^{8,38}$; and lymphocytic infection has been detected ${ }^{25}$
Shown using isolated

MHV-3-induced FGL2 expression is crucial for liver necrosis; in MHV-JHM-infected mice, IFN- $\gamma$ is required for $\mathrm{CD}^{+}{ }^{+}$T-cell-mediated responses ${ }^{61,77,89}$; and in FIPV infection, increased cytokine concentrations are present in blood and tissues during exacerbation of disease ${ }^{49,112,113}$

MHV does not induce type I IFN expression ${ }^{114,115}$

In FIPV infection, lymphopaenia is present during clinical relapses ${ }^{42}$; and in MHV-3 infection, lymphopaenia is present and lymphocytic infection has been detected ${ }^{28}$

Haemophagocytosis Present in severe cases ${ }^{21,22} \quad$ Not reported

CNS, central nervous system; DC, dendritic cell; FGL2, fibrinogen-like protein 2; FIPV, feline infectious peritonitis virus; IBV, avian infectious bronchitis virus; IFN, interferon; MHV, murine hepatitis virus; MHV-JHM, MHV strain JHM; SARS, severe acute respiratory syndrome; SARS-CoV, SARS coronavirus.

\section{Avian coronavirus infections}

Role of robust innate immune response in acute respiratory disease. Avian infectious bronchitis virus (IBV) causes marked respiratory disease, especially in young chickens $^{92,93}$. Similar to SARS-CoV, IBV also infects organs other than the respiratory tract. IBV replicates in the gastrointestinal tract, but infection of the gut does not usually result in clinically evident disease. IBV also infects the kidneys, and some strains of virus cause severe nephritis, which results in a high rate of mortality ${ }^{92,93}$. At present, there is no evidence that IBV infects macrophages. It is clear that virus-induced cytolytic destruction accounts for many of the pathological changes that are observed in this infection. However, there are indications that an immunopathogenic component contributes to IBV-induced disease.

Much of the respiratory disease that is observed in young chickens with severe clinical signs is a result of mucosal thickening and excessive production of a thick mucus in the airways, which asphyxiates the infected host $^{92}$. Although it has not been proven for IBV-infected chickens, it is probable that this excessive production of mucus is mediated by several cytokines, such as IL-1 $\beta$, IL-6 and CXCL8, which are secreted by infected epithelial cells in other respiratory-virus infections ${ }^{94}$. CXCL8 is an attractant for neutrophils, which are one of the main cellular components of the nasal exudates that are found in infected chickens. Neutrophil depletion by 5-fluorouracil has been shown to reduce the thickness of the nasal exudate, thereby diminishing epithelial-cell damage and cilia loss ${ }^{95}$. Similarly, the early stages of renal disease are characterized by a massive infiltration of neutrophils ${ }^{96}$. Collectively, these observations indicate that the cellular innate immune response to the virus is an important factor in the development of severe disease.

Chronic lymphocytic nephritis. Under certain conditions (depending on age at time of inoculation, and strain of IBV and of chicken), IBV causes a persistent infection, with an interstitial lymphocytic nephritis in the kidneys ${ }^{92,93,97}$. Similar to the MHV-infected CNS, lymphocytic infiltration and ongoing renal damage have been shown when viral loads are low or undetectable ${ }^{97}$. The precise roles of persistent virus and the host immune response in IBV-induced renal disease are not known, but by analogy with other coronavirus infections, it is probable that the chronic nephritis that is observed in these animals is partially immune mediated.

\section{An immunopathogenic component in SARS?}

Several features of SARS indicate, but do not prove, that the host immune response contributes to disease; these have been described in detail in previous sections and are summarized in TABLE 2. However, as also outlined in this Review, the pathogenesis of 
several animal coronaviruses includes an immunemediated component. It is therefore reasonable to suggest that similar mechanisms occur in SARS. Clearly, it is crucial to determine the extent to which the pathological changes that are observed in SARS result from direct destruction by virus compared with immune-mediated elimination of infected cells. In FIPV-infected domestic cats, increased viral replication initiates a cascade of events that leads to injury to the immune system, as well as to several organs ${ }^{42,43}$, whereas in mice with MHV-mediated demyelination, clinical disease and myelin destruction increase as virus is cleared $\mathrm{d}^{70,71,76}$. In patients with SARS, virus is detected in the lungs and in immune cells at the time of death, indicating that virus directly causes pulmonary and immune-system injury ${ }^{25-27}$. However, the kinetics of viral clearance from sites of infection in individual patients need to be established before the role of the host immune response in the disease process can be fully evaluated.

Several features that are common to animals infected with FIPV or MHV and to patients infected with SARS-CoV are consistent with immunopathological disease. These include the propensity of virus to infect macrophages and DCs, and the presence of increased, and perhaps pathological, systemic concentrations of chemokines and other cytokines. In animals infected with MHV or FIPV, activated macrophages are present at sites of inflammation and participate in tissue destruction ${ }^{40,62,70}$. Activated macrophages are also present in the lungs of SARS$\mathrm{CoV}$-infected individuals. SARS-CoV-infected macrophages and DCs express increased amounts of pro-inflammatory cytokines ${ }^{30,32,34}$. Consistent with this, increased concentrations of pro-inflammatory chemokines and other cytokines are present in most infected patients ${ }^{35-37,39}$, and by analogy with other coronavirus infections, as well with ARDS (adult respiratory distress syndrome $)^{98}$, expression of these pro-inflammatory mediators might contribute to disease.

Another immunopathological mechanism, antibody-dependent enhancement of disease, is observed in immunized domestic cats after challenge with FIPV ${ }^{55}$, and it occurs when tissue-culture cells are exposed to recombinant viral vectors that are coated with the SARS-CoV spike protein ${ }^{99}$. However, this phenomenon has not been shown in most immunization studies ${ }^{7}$, and it needs to be confirmed using infectious SARS-CoV.

\section{Future directions}

Fortunately, the world has not witnessed a re-emergence of SARS since 2003. To be prepared for any outbreak that might occur in the future, it is crucial to understand the pathogenesis of this disease. In vitro studies will be useful for investigating how SARS-CoV modifies gene expression in primary target cells, such as macrophages, DCs, lymphocytes and pulmonary epithelial cells. However, many of the outstanding issues that have been discussed in this Review will be answered only in the context of SARS-CoV-infected animals or humans. Particularly in the absence of any resurgence of disease in humans, it will be most important to develop an animal model that accurately reproduces the human infection.

Current animal models of coronavirus infection are useful for testing vaccines and antiviral drugs, but they do not reproduce the pulmonary or immunesystem disease that is observed in individuals with SARS $^{7}$. Although SARS-CoV replicates in the lungs of mice, hamsters and domestic cats, these animals remain asymptomatic ${ }^{100-103}$. Initial reports indicated that cynomolgus macaques (Macaca fascicularis) and ferrets develop clinically evident respiratory disease and would therefore be useful animal models for studying SARS; however, these results have not been reproducible ${ }^{101,104-108}$. Only an animal model will allow investigators to determine the relationship of viral load to disease outcome, as well as to evaluate fully the role of infection and dysfunction of macrophages and lymphocytes in the disease process. In the case of another human coronavirus, $\mathrm{HCoV}-229 \mathrm{E}$, development of a mouse model of infection required transgenic expression of the human host-cell receptor (CD13), disruption of the innate immune response of the mouse and adaptation of the virus to growth in CD13-expressing mouse cells ${ }^{109}$. Mouse and rat ACE2 molecules are less-efficient receptors for SARS-CoV than is human ACE2 (REF. 110), and the development of a useful murine model of SARS will probably require transgenic expression of human ACE2. However, by analogy with the mouse model of HCoV-229E infection, the development of a transgenic mouse might be only the first step towards developing a useful murine model. The knowledge gained from the study of an animal model will facilitate the development of specific therapies that are designed to minimize pulmonary disease and optimize the anti-SARS-CoV immune response, whether it be excessive (but not necessarily dysregulated), suppressed or both.
1. Griffin, D. E. Immune responses during measles virus infection. Curr. Top. Microbiol. Immunol. 191, 117-134 (1995).

2. Rehermann, B. \& Nascimbeni, M. Immunology of hepatitis $B$ virus and hepatitis $C$ virus infection. Nature Rev. Immunol. 5, 215-229 (2005).

3. Mejias, A., Chavez-Bueno, S. \& Ramilo, O. Respiratory syncytial virus pneumonia: mechanisms of inflammation and prolonged airway hyperresponsiveness. Curr. Opin. Infect. Dis. 18, 199-204 (2005).

4. Banerjee, S., Narayanan, K., Mizutani, T. \& Makino, S. Murine coronavirus replication-induced p38 mitogenactivated protein kinase activation promotes interleukin- 6 production and virus replication in cultured cells. J. Virol. 76, 5937-5948 (2002).

5. Menasche, G., Feldmann, J., Fischer, A. \& de Saint Basile, G. Primary hemophagocytic syndromes point to a direct link between lymphocyte cytotoxicity and homeostasis. Immunol. Rev. 203, 165-179 (2005).

6. Parr, R. L. et al. Association of mouse fibrinogen-like protein with murine hepatitis virus-induced prothrombinase activity. J. Virol. 69, 5033-5038 (1995).

7. Peiris, J. S., Guan, Y. \& Yuen, K. Y. Severe acute respiratory syndrome. Nature Med. 10, S88-S97 (2004).
8. Peiris, J. S., Yuen, K. Y., Osterhaus, A. D. \& Stohr, K The severe acute respiratory syndrome. N. Engl. J. Med. 349, 2431-2441 (2003)

9. Lai, M. M. C. \& Cavanagh, D. The molecular biology of coronaviruses. Adv. Virus Res. 48, 1-100 (1997).

10. van der Hoek, L. et al. Identification of a new human coronavirus. Nature Med. 10, 368-373 (2004).

11. Fouchier, R. A. et al. A previously undescribed coronavirus associated with respiratory disease in humans. Proc. Natl Acad. Sci. USA 101, 6212-6216 (2004).

12. Woo, P. C. et al. Characterization and complete genome sequence of a novel coronavirus, coronavirus HKU1, from patients with pneumonia. J. Virol. 79, 884-895 (2005). 
13. Guan, Y. et al. Isolation and characterization of viruses related to the SARS coronavirus from animals in southern China. Science 302, 276-278 (2003).

14. Chinese SARS Molecular Epidemiology Consortium. Molecular evolution of the SARS coronavirus during the course of the SARS epidemic in China. Science 303, 1666-1669 (2004)

\section{References 13 and 14 trace the evolution of} SARS-CoV in human and masked palm-civet populations.

15. Song, H. D. et al. Cross-host evolution of severe acute respiratory syndrome coronavirus in palm civet and human Proc. Natl Acad. Sci. USA 102, 2430-2435 (2005).

16. Hamming, I. et al. Tissue distribution of ACE2 protein, the functional receptor for SARS coronavirus. A first step in understanding SARS pathogenesis. J. Pathol. 203, 631-637 (2004).

17. Li, W. et al. Angiotensin-converting enzyme 2 is a functional receptor for the SARS coronavirus. Nature 426, 450-454 (2003)

18. Kuba, K. et al. A crucial role of angiotensin converting enzyme 2 (ACE2) in SARS coronavirus-induced lung injury. Nature Med. 11, 875-879 (2005).

19. Imai, $Y$, et al. Angiotensin-converting enzyme 2 protects from severe acute lung failure. Nature 436, 112-116 (2005).

20. Wong, R. S. et al. Haematological manifestations in patients with severe acute respiratory syndrome: retrospective analysis. BMJ 326, 1358-1362 (2003).

21. Wang, J. T. et al. Clinical manifestations, laboratory findings, and treatment outcomes of SARS patients. Emerg. Infect. Dis. 10, 818-824 (2004).

22. Nicholls, J. M. et al. Lung pathology of fatal severe acute respiratory syndrome. Lancet 361, 1773-1778 (2003).

23. Chan, K. H. et al. Detection of SARS coronavirus in patients with suspected SARS. Emerg. Infect. Dis. 10, 294-299 (2004).

24. Peiris, J. S. et al. Clinical progression and viral load in a community outbreak of coronavirus-associated SARS pneumonia: a prospective study. Lancet 361, 1767-1772 (2003).

25. Gu, J. et al. Multiple organ infection and the pathogenesis of SARS. J. Exp. Med. 202, 415-424 (2005). This is an important histopathological study that indicates that SARS-CoV infection of lymphocytes is a crucial determinant of disease outcome.

26. Farcas, G. A. et al. Fatal severe acute respiratory syndrome is associated with multiorgan involvement by coronavirus. J. Infect. Dis. 191, 193-197 (2005).

27. Mazzulli, T. et al. Severe acute respiratory syndromeassociated coronavirus in lung tissue. Emerg. Infect. Dis. 10, 20-24 (2004).

28. Lamontagne, L., Descoteaux, J. P. \& Jolicoeur, P. Mouse hepatitis virus 3 replication in T and B lymphocytes correlate with viral pathogenicity. J. Immunol. 142, 4458-4465 (1989)

29. Franks, T. J. et al. Lung pathology of severe acute respiratory syndrome (SARS): a study of 8 autopsy cases from Singapore. Hum. Pathol. 34, 743-748 (2003).

30. Cheung, C. Y. et al. Cytokine responses in severe acute respiratory syndrome coronavirus-infected macrophages in vitro: possible relevance to pathogenesis. J. Virol. $\mathbf{7 9}$ 7819-7826 (2005).

31. Yilla, M. et al. SARS-coronavirus replication in human peripheral monocytes/macrophages. Virus Res. 107 93-101 (2005).

32. Tseng, C. T., Perrone, L. A., Zhu, H., Makino, S. \& Peters, C. J. Severe acute respiratory syndrome and the innate immune responses: modulation of effector cell function without productive infection. J. Immunol. 174, 7977-7985 (2005)

33. Spiegel, M. et al. Inhibition of $\beta$ interferon induction by severe acute respiratory syndrome coronavirus suggests a two-step model for activation of interferon regulatory factor 3. J. Virol. 79, 2079-2086 (2005).

\section{This was the first description of the mechanism} of type I IFN suppression of a coronavirus.

34. Law, H. K. et al. Chemokine upregulation in SARS coronavirus infected human monocyte derived dendritic cells. Blood 106, 2366-2374 (2005)

35. Wong, C. K. et al. Plasma inflammatory cytokines and chemokines in severe acute respiratory syndrome. Clin. Exp. Immunol. 136, 95-103 (2004).

36. Wang, W. K. et al. Temporal relationship of viral load, ribavirin, interleukin (IL)-6, IL-8, and clinical progression in patients with severe acute respiratory syndrome. Clin. Infect. Dis. 39, 1071-1075 (2004)

37. Zhang, Y. et al. Analysis of serum cytokines in patients with severe acute respiratory syndrome. Infect. Immun. 72, 4410-4415 (2004).
38. Tsui, P. T., Kwok, M. L., Yuen, H. \& Lai, S. T. Severe acute respiratory syndrome: clinical outcome and prognostic correlates. Emerg. Infect. Dis. 9, 1064-1069 (2003).

39. Lee, C. H. et al. Altered p38 mitogen-activated protein kinase expression in different leukocytes with increment of immunosuppressive mediators in patients with severe acute respiratory syndrome. J. Immunol. 172, 7841-7847 (2004).

40. de Groot, R. J. \& Horzinek, M. C. in The Coronaviridae (ed. Siddell, S.) 293-315 (Plenum, New York, 1995)

41. Stoddart, C. A. \& Scott, F. W. Intrinsic resistance of feline peritoneal macrophages to coronavirus infection correlates with in vivo virulence. J. Virol. 63, 436-440 (1989).

42. de Groot-Mijnes, J. D., van Dun, J. M., van der Most, R. G. \& de Groot, R. J. Natural history of a recurrent feline coronavirus infection and the role of cellular immunity in survival and disease. J. Virol. 79, 1036-1044 (2005). This is a careful study of the clinical and immunological characteristics of FIP.

43. Hoskins, J. D. Coronavirus infection in cats. Vet. Clin. North Am. Small Anim. Pract. 23, 1-16 (1993).

44. Tresnan, D. B., Levis, R. \& Holmes, K. V. Feline aminopeptidase $\mathrm{N}$ serves as a receptor for feline, canine, porcine, and human coronaviruses in serogroup I. J. Virol. 70, 8669-8674 (1996).

45. Dean, G. A., Olivry, T., Stanton, C. \& Pedersen, N. C. In vivo cytokine response to experimental feline infectious peritonitis virus infection. Vet. Microbiol. 97, 1-12 (2003)

46. Haagmans, B., Egberink, H. \& Horzinek, M. Apoptosis and T-cell depletion during feline infectious peritonitis. J. Virol. 70, 8977-8983 (1996).

47. Kipar, A. et al. Histopathological alterations of lymphatic tissues in cats without feline infectious peritonitis after long-term exposure to FIP virus. Vet. Microbiol. 69, 131-137 (1999).

48. Zheng, L. et al. Induction of apoptosis in mature T cells by tumour necrosis factor. Nature $\mathbf{3 7 7}$, 348-351 (1995).

49. Kiss, I., Poland, A. M. \& Pedersen, N. C. Disease outcome and cytokine responses in cats immunized with an avirulent feline infectious peritonitis virus (FIPV)-UCD1 and challenge-exposed with virulent FIPV-UCD8. J. Feline Med. Surg. 6, 89-97 (2004)

50. Kipar, A., Kohler, K., Leukert, W. \& Reinacher, M. A comparison of lymphatic tissues from cats with spontaneous feline infectious peritonitis (FIP), cats with FIP virus infection but no FIP, and cats with no infection. J. Comp. Pathol. 125, 182-191 (2001).

51. Paltrinieri, S., Cammarata, M. P., Cammarata, G. \& Comazzi, S. Some aspects of humoral and cellular immunity in naturally occuring feline infectious peritonitis. Vet. Immunol. Immunopathol. 65, 205-220 (1998).

52. Kipar, A., Bellmann, S., Kremendahl, J., Kohler, K. \& Reinacher, M. Cellular composition, coronavirus antigen expression and production of specific antibodies in lesions in feline infectious peritonitis. Vet. Immunol. Immunopathol. 65, 243-257 (1998).

53. Jacobse-Geels, H. E., Daha, M. R. \& Horzinek, M. C. Antibody, immune complexes, and complement activity fluctuations in kittens with experimentally induced feline infectious peritonitis. Am. J. Vet. Res. 43, 666-670 (1982).

54. Weiss, R. C. \& Scott, F. W. Antibody-mediated enhancement of disease in feline infectious peritonitis: comparisons with dengue hemorrhagic fever. Comp. Immunol. Microbiol. Infect. Dis. 4, 175-189 (1981).

55. Vennema, H. et al. Early death after feline infectious peritonitis virus challenge due to recombinant vaccinia virus immunization. J. Virol. 64, 1407-1409 (1990). This work clearly shows that immunization with vaccinia virus expressing FIPV spike protein results in more severe disease after infection with FIPV.

56. Lavi, E., Gilden, D., Wroblewska, Z., Rorke, L. \& Weiss, S. Experimental demyelination produced by the A59 strain of MHV. Neurology 34, 597-603 (1984).

57. Lampert, P. W., Sims, J. K. \& Kniazeff, A. J. Mechanism of demyelination in JHM virus encephalomyelitis. Acta Neuropathol. 24, 76-85 (1973).

58. Weiner, L. P. Pathogenesis of demyelination induced by a mouse hepatitis virus (JHM virus). Arch. Neurol. 28, 298-303 (1973)

59. Stohlman, S. A., Bergmann, C. C. \& Perlman, S. in Persistent Viral Infections (eds Ahmed, R. \& Chen, I.) 537-557 (Wiley \& Sons, New York, 1998).

60. Perlman, S. Pathogenesis of coronavirus-induced infections: review of pathological and immunological aspects. Adv. Exp. Med. Biol. 440, 503-513 (1998).

61. Bergmann, C. C. et al. Perforin and $\gamma$ interferon-mediated control of coronavirus central nervous system infection by CD8 T cells in the absence of CD4 T cells. J. Virol. 78, 1739-1750 (2004)

62. Wu, G. F. \& Perlman, S. Macrophage infiltration, but not apoptosis, is correlated with immune-mediated demyelination following murine infection with a neurotropic coronavirus. J. Virol. 73, 8771-8780 (1999).

63. Wang, F., Stohlman, S. A. \& Fleming, J. O. Demyelination induced by murine hepatitis virus $\mathrm{JHM}$ strain $(\mathrm{MHV}-4)$ is immunologically mediated. J. Neuroimmunol. $\mathbf{3 0}, \mathbf{3 1 - 4 1}$ (1990).

64. Houtman, J. J. \& Fleming, J. O. Dissociation of demyelination and viral clearance in congenitally immunodeficient mice infected with murine coronavirus JHM. J. Neurovirol. 2, 101-110 (1996).

References 61-64, together with reference 72 show that MHV-JHM-induced demyelination is mainly immune mediated.

65. Lin, M. T., Hinton, D. R., Marten, N. W., Bergmann, C. C. \& Stohlman, S. A. Antibody prevents virus reactivation within the central nervous system. J. Immunol. 162, 7358-7368 (1999).

66. Lin, M. T., Stohlman, S. A. \& Hinton, D. R. Mouse hepatitis virus is cleared from the central nervous systems of mice lacking perforin-mediated cytolysis. J. Virol. 71, 383-391 (1997).

67. Parra, B. et al. IFN- $\gamma$ is required for viral clearance from central nervous system oligodendroglia. J. Immunol. 162, 1641-1647 (1999).

68. Fleming, J. O., Trousdale, M. D., El-Zaatari, F., Stohlman, S. A. \& Weiner, L. P. Pathogenicity of antigenic variants of murine coronavirus $\mathrm{JHM}$ selected with monoclonal antibodies. J. Virol. 58, 869-875 (1986).

69. Watanabe, R., Wege, H. \& ter Meulen, V. Adoptive transfer of EAE-like lesions from rats with coronavirus-induced demyelinating encephalomyelitis. Nature 305, 150-153 (1983).

70. Stohlman, S. A. \& Hinton, D. R. Viral induced demyelination. Brain Pathol. 11, 92-106 (2001).

71. Wang, F.-I., Hinton, D., Gilmore, W., Trousdale, M. \& Fleming, J. O. Sequential infection of glial cells by the murine hepatitis virus $\mathrm{JHM}$ strain (MHV-4) leads to a characteristic distribution of demyelination. Lab. Invest. 66, 744-754 (1992).

72. Wu, G. F., Dandekar, A. A., Pewe, L. \& Perlman, S. CD4 and CD8 T cells have redundant but not identical roles in virus-induced demyelination. J. Immunol. 165, 2278-2286 (2000).

73. Gombold, J., Sutherland, R., Lavi, E., Paterson, Y. \& Weiss, S. R. Mouse hepatitis virus A59-induced demyelination can occur in the absence of CD8 ${ }^{+} \mathrm{T}$ cells. Microb. Pathog. 18, 211-221 (1995).

74. Haring, J. S., Pewe, L. L. \& Perlman, S. Bystander CD8 $T$ cell-mediated demyelination after viral infection of the central nervous system. J. Immunol. 169, 1550-1555 (2002).

75. Kim, T. S. \& Perlman, S. Virus-specific antibody, in the absence of $T$ cells, mediates demyelination in mice infected with a neurotropic coronavirus. Am. J. Pathol. 166, 801-809 (2005)

76. Kim, T. S. \& Perlman, S. Viral expression of CCL2 is sufficient to induce demyelination in RAG1 $1^{-/-}$mice infected with a neurotropic coronavirus. J. Virol. 79, 7113-7120 (2005).

77. Pewe, L. L. \& Perlman, S. CD8 T cell-mediated demyelination is IFN- $\gamma$ dependent in mice infected with a neurotropic coronavirus. J. Immunol. 168, 1547-1551 (2002).

78. Pewe, L., Haring, J. \& Perlman, S. CD4 T-cell-mediated demyelination is increased in the absence of $\gamma$ interferon in mice infected with mouse hepatitis virus. J. Virol. 76 , 7329-7333 (2002).

79. Chen, B. P., Kuziel, W. A. \& Lane, T. E. Lack of CCR2 results in increased mortality and impaired leukocyte activation and trafficking following infection of the central nervous system with a neurotropic coronavirus. J. Immunol. 167, 4585-4592 (2001).

80. Glass, W. G. et al. Antibody targeting of the CC chemokine ligand 5 results in diminished leukocyte infiltration into the central nervous system and reduced neurologic disease in a viral model of multiple sclerosis. J. Immunol. 172, 4018-4025 (2004)

81. Liu, M. T., Armstrong, D., Hamilton, T. A. \& Lane, T. E. Expression of MIG (monokine induced by interferon- $\gamma$ ) is important in T lymphocyte recruitment and host defense following viral infection of the central nervous system. J. Immunol. 166, 1790-1795 (2001).

82. Liu, M. T. et al. The T cell chemoattractant IFN-inducible protein 10 is essential in host defense against viral-induced neurologic disease. J. Immunol. 165, 2327-2330 (2000).

83. Knobler, R. L., Tunison, L. A. \& Oldstone, M. B. Host genetic control of mouse hepatitis virus type 4 (JHM strain) replication. I. Restriction of virus amplification and spread in macrophages from resistant mice. J. Gen. Virol. 65 1543-1548 (1984) 
84. Xue, S., Sun, N., van Rooijen, N. \& Perlman, S. Depletion of blood-borne macrophages does not reduce demyelination in mice infected with a neurotropic coronavirus. J. Virol. 73, 6327-6334 (1999).

85. Yuwaraj, S., Cattral, M., Pope, M. \& Levy, G. Murine hepatitis virus: molecular biology and pathogenesis. Viral Hep. Rev. 2, 125-142 (1996).

86. Coutelier, J. P. et al. B lymphocyte and macrophage expression of carcinoembryonic antigen-related adhesion molecules that serve as receptors for murine coronavirus. Eur. J. Immunol. 24, 1383-1390 (1994).

87. Pope, M. et al. Pattern of disease after murine hepatitis virus strain 3 infection correlates with macrophage activation and not viral replication. J. Virol. 69, 5252-5260 (1995).

88. Ding, J. W. et al. Fulminant hepatic failure in murine hepatitis virus strain 3 infection: tissue-specific expression of a novel fgl2 prothrombinase. J. Virol. 71, 9223-9230 (1997).

89. Marsden, P. A. et al. The Fgl2/fibroleukin prothrombinase contributes to immunologically mediated thrombosis in experimental and human viral hepatitis. J. Clin. Invest. 112, 58-66 (2003).

This work uses FGL2-deficient mice to show the crucial role of this prothrombinase in liver necrosis

90. McGilvray, I. D. et al. Murine hepatitis virus strain 3 induces the macrophage prothrombinase $f g l-2$ through p38 mitogen-activated protein kinase activation J. Biol. Chem. 273, 32222-32229 (1998).

91. Ning, Q. et al. Induction of prothrombinase fg/2 by the nucleocapsid protein of virulent mouse hepatitis virus is dependent on host hepatic nuclear factor- $4 \alpha$. J. Biol. Chem. 278, 15541-15549 (2003).

92. Raj, G. D. \& Jones, R. C. Infectious bronchitis virus: immunopathogenesis of infection in the chicken. Avian Pathol. 26, 677-706 (1997).

93. Cavanagh, D. Severe acute respiratory syndrome vaccine development: experiences of vaccination against avian infectious bronchitis coronavirus. Avian Pathol. 32, 567-582 (2003).

94. Hendley, J. O. The host response, not the virus, causes the symptoms of the common cold. Clin. Infect. Dis. 26, 847-848 (1998).

95. Raj, G. D., Savage, C. E. \& Jones, R. C. Effect of heterophil depletion by 5 -fluorouracil on infectious bronchitis virus infection in chickens. Avian Pathol. 26, 427-432 (1997).
96. Chen, B. Y, Hosi, S. Nunoya, T. \& Otakura, C. Histopathology and immunochemistry of renal lesions due to infectious bronchitis virus in chickens. Avian Pathol. 25, 269-283 (1996).

97. Lee, C., Brown, C., Hilt, D. A. \& Jackwood, M. W. Nephropathogenesis of chickens experimentally infected with various strains of infectious bronchitis virus. Avian Pathol. 66, 835-840 (2004).

98. Ware, L. B. \& Matthay, M. A. The acute respiratory distress syndrome. N. Engl. J. Med. 342, 1334-1349 (2000).

99. Yang, Z. Y. et al. Evasion of antibody neutralization in emerging severe acute respiratory syndrome coronaviruses. Proc. Natl Acad. Sci. USA 102, 797-801 (2005).

100. Subbarao, K. et al. Prior infection and passive transfer of neutralizing antibody prevent replication of severe acute respiratory syndrome coronavirus in the respiratory tract of mice. J. Virol. 78, 3572-3577 (2004)

101. Martina, B. E. et al. SARS virus infection of cats and ferrets. Nature 425, 915 (2003)

102. Glass, W. G., Subbarao, K., Murphy, B. \& Murphy, P. M. Mechanisms of host defense following severe acute respiratory syndrome-coronavirus (SARS-CoV) pulmonary infection of mice. J. Immunol. 173, 4030-4039 (2004).

103. Roberts, A. et al. Severe acute respiratory syndrome coronavirus infection of Golden Syrian hamsters. J. Virol. 79, 503-511 (2005).

104. Fouchier, R. A. et al. Koch's postulates fulfilled for SARS virus. Nature 423, 240 (2003).

105. Weingartl, $H$. et al. Immunization with modified vaccinia virus Ankara-based recombinant vaccine against severe acute respiratory syndrome is associated with enhanced hepatitis in ferrets. J. Virol. 78, 12672-12676 (2004)

106. McAuliffe, J. et al. Replication of SARS coronavirus administered into the respiratory tract of African Green, rhesus and cynomolgus monkeys. Virology $\mathbf{3 3 0}, 8-15$ (2004).

107. Rowe, T. et al. Macaque model for severe acute respiratory syndrome. J. Virol. 78, 11401-11404 (2004).

108. Kuiken, T. et al. Newly discovered coronavirus as the primary cause of severe acute respiratory syndrome. Lancet 362, 263-270 (2003).

109. Lassnig, C. et al. Development of a transgenic mouse model susceptible to human coronavirus 229E. Proc. Natl Acad. Sci. USA 102, 8275-8280 (2005).

110. Li, W. et al. Efficient replication of severe acute respiratory syndrome coronavirus in mouse cells is limited by murine angiotensin-converting enzyme 2 . J. Virol. 78, 11429-11433 (2004)

111. Dandekar, A. A., Anghelina, D. \& Perlman, S. Bystander CD8 T-cell-mediated demyelination is interferon- $\gamma$ dependent in a coronavirus model of multiple sclerosis. Am. J. Pathol. 164, 363-369 (2004).

112. Goitsuka, R. et al. IL-6 activity in feline infectious peritonitis. J. Immunol. 144, 2599-2603 (1990).

113. Foley, J. E., Rand, C. \& Leutenegger, C. Inflammation and changes in cytokine levels in neurological feline infectious peritonitis. J. Feline Med. Surg. 5, 313-322 (2003).

114. Garlinghouse, L. E. Jr, Smith, A. L. \& Holford, T. The biological relationship of mouse hepatitis virus (MHV) strains and interferon: in vitro induction and sensitivities. Arch. Virol. 82, 19-29 (1984).

115. Pewe, L. et al. A severe acute respiratory syndromeassociated coronavirus-specific protein enhances virulence of an attenuated murine coronavirus. J. Virol. 79, 1133511342 (2005).

Acknowledgements

We thank J. Harty, T. Gallagher, S. Varga and N. Butler for comments. This work was supported by the National Institutes of Health (United States) and the National Multiple Sclerosis Society (United States).

Competing interests statement

The authors declare no competing financial interests.

\section{(2) Online links}

DATABASES

The following terms in this article are linked online to: Entrez Gene:

http://www.ncbi.nlm.nih.gov/entrez/query.fcgi?db=gene ACE2 | CCL2 | CD66 | CXCL8 | CXCL10 | FGL2 | IL-6 | IRF3 | p38MAPK | spike

Infectious diseases information:

http://www.cdc.gov/ncidod/diseases/index.htm SARS

\section{FURTHER INFORMATION}

Stanley Perlman's homepage:

http://immuno.grad.uiowa.edu/faculty/facultydetail.asp?!D=21

Access to this interactive links box is free online. 